\title{
Endometritis in the bitch: Immunohistochemical localization of cyclooxygenase 2
}

\author{
María Carla García Mitacek ${ }^{1,2}$, Romina Gisele Praderio ${ }^{1,2}$, María Cecilia Stornelli ${ }^{1}$, Rodolfo Luzbel de la Sota ${ }^{1,2}$ and \\ María Alejandra Stornelli ${ }^{*}$ \\ ${ }^{1}$ Cátedra y Servicio de Reproducción Animal, Facultad de Ciencias Veterinarias, Universidad Nacional de La Plata, \\ La Plata, Argentina \\ ${ }^{2}$ CONICET, CABA, Buenos Aires, Argentina
}

\begin{abstract}
Background: In several mammals, subfertility or infertility associated with endometritis was reported. Although there have been studies about endometritis in bitches, the pathophysiological mechanisms are not completely known.

Aim: This study aimed to evaluate the immunohistochemical expression of Cyclooxygenase 2 (COX2) in clinically healthy bitches with normal uterine tissue and bitches with endometritis.

Methods: Forty-eight mixed breed bitches in diestrus were used. Uterine biopsies were collected for diagnosis [normal endometrium $(n=15$; NE), cystic endometrial hyperplasia $(n=1)$, atrophy $(n=2)$, acute endometritis $(n=9$; AE), subacute endometritis $(n=7$; SE), and chronic endometritis $(n=14$; CE)]. Immunostaining and quantification of positively stained cells was performed on full-thickness uterine biopsies. Data were analyzed by the GLIMMIX procedure of SAS.

Results: COX2 immunostaining was scattered and restricted to cells in the stroma in bitches with NE. However, in bitches with endometritis, strong staining was observed in the luminal epithelium, glandular epithelium, and stromal cells. Staining was also observed in inflammatory cells localized in the stroma as well as inside of the glands. The percentage of COX2 positive stromal cells in bitches with AE, SE, and CE was significantly higher compared with NE $(p<0.005)$. In addition, the percentage of COX2 positive stromal cells in bitches with SE, and CE was significantly lower compared with AE $(p<0.003)$.

Conclusion: COX2 could be involved in the pathophysiological mechanisms producing endometritis without the presence of cystic endometrial hyperplasia in bitches. However, further researches on this topic are required.

Keywords: Bitch, COX2, Endometritis, Immunohistochemical.
\end{abstract}

\section{Introduction}

Diseases of the canine uterus were studied by several researchers. The most prevalent uterine lesions in the bitch are endometritis, cystic endometrial hyperplasia, and cystic endometrial hyperplasia-pyometra complex (De Bosschere et al., 2001; Silva et al., 2010; Bukowska et al., 2014; Gifford et al., 2014; Hagman, 2017; Praderio et al., 2019). It was reported that clinically healthy bitches (CHB) with normal vaginal cytology could suffer endometritis, showing in the histopathological study inflammation of the endometrial tissue (Fontaine et al., 2009; Mir et al., 2013). Some researchers think that cystic endometrial hyperplasia and endometritis occurred together, but in some cases, cystic endometrial hyperplasia occurred without endometritis (Dow, 1959; Gifford et al., 2014). Moreover, bitches with cystic endometrial hyperplasia-pyometra complex show several clinical signs (Haas et al., 2016). In the last years, it has been observed that several mammals with subfertility or infertility as the only clinical sign suffer endometritis. Although endometritis had been reported in $\mathrm{CHB}$, the pathophysiological mechanisms it is not completely known (Fontaine et al., 2009; Mir et al., 2013; Gifford et al., 2014). Cyclooxygenase 2 (COX2) is a prostaglandin synthesis enzyme, and it is induced during the inflammation. Thus, the increase in prostaglandin production because the over-expression of COX2 could be impairing the implantation of fertilized oocytes because an abnormality in the endometrium (Ota et al., 2001). It has been reported that COX2 expression may be abnormal in several reproductive diseases, such as pyometra and endometriosis (Ota et al., 2001; Silva et al., 2010). In this sense, Silva et al. (2010) reported that COX2 immunostaining was observed in luminal epithelium, glandular epithelium, and stromal cells in bitches with pyometra. In addition, staining was also observed in inflammatory cells localized in the stroma as well as in glandular lumen. Besides, in bitches with normal endometria COX2 immunostaining was observed in the cells of the stroma and small capillaries (Silva et al., 2010). Therefore, it is probably that normal uterus and uterus with endometritis without cystic endometrial hyperplasia in $\mathrm{CHB}$ show different immunostaining patters. 
The aim was to evaluate the immunohistochemical expression of $\mathrm{COX} 2$ in the endometrium of $\mathrm{CHB}$ with a normal uterus and in $\mathrm{CHB}$ with endometritis without the presence of cystic endometrial hyperplasia.

\section{Materials and Methods}

Forty-eight mixed breed, privately owned, intact, CHB, in diestrus, aged between 1-5 years and weighing between 10 and $30 \mathrm{~kg}$ were used in this study. Bitches were included in a program for breeding control at a municipal pet public shelter in the city of La Plata. Ovariohysterectomy was performed between 15 and 50 days after the end of the estrus. All bitches enrolled in the study were undergoing a thorough clinical and reproductive examination and were clinically healthy. Diestrus was determined based on the history provided by the owner and confirmed in each bitch based on ovarian structures, serum progesterone $\left(\mathrm{P}_{4}\right)$, and vaginal cytology (Feldman and Nelson, 2000). Blood samples were centrifuged and stored at $-20^{\circ} \mathrm{C}$ until $\mathrm{P}_{4}$ was measured by chemiluminescence immunoassay (Elecsys ${ }^{\circledR}$, Progesterone II; Roche, Mannheim, Germany). The intra-assay CVs for high-pool and low-pool $\mathrm{P}_{4}(4.87$ and $0.3 \mathrm{ng} / \mathrm{ml})$ were $4.5 \%$ and $2 \%$, respectively. Vaginal cytology was stained with Tinción $15^{\circledR}$ (Biopur, Rosario) and was examined at $10 \times$ and $40 \times$ magnification. The experiment had the approval of the IACUC of FCV UNLP (40-4-14 B). After ovariohysterectomy (OVX), uterine biopsy samples were collected from the middle part of both horns. The samples were fixed in $10 \%$ buffered formalin, dehydrated, and embedded in paraffin. Then, sections were cut at 2-4 $\mu \mathrm{m}$, deparaffinized and stained with $\mathrm{H} \& \mathrm{E}$, and were observed with a light microscope at $10 \times$ and $40 \times$ magnifications (Olympus, Tokyo, Japan; Schlafer and Miller, 2007).

After biopsies were classified, samples from normal uterine tissue and uterus with endometritis without the presence of cystic endometrial hyperplasia were select to perform the immunohistochemical study (Fig. 1). Immunostaining and quantification of positively stained cells were performed on full-thickness uterine biopsies. Sections were cut from paraffin embedded tissues and mounted on slides. Tissues were deparaffinized, rehydrated, and washed under running tap water (5 minutes). Immunohistochemical detection of COX2 was performed by an immunoperoxidase method using COX2 polyclonal primary antibody (1:200, aa 584598; Cayman Chemica, Ann Arbor, MI) according to the manufacturer's instructions (Kowalewski et al., 2006; Santelices Iglesias et al., 2018). For negative control, the primary antibody was replaced with PBS. For positive control, was used the macula densa of sections of dog kidney (Fig. 2). Revealing was achieved using a chromogenic solution (3, 30-diaminobenzidine tetrahydrochloride; Dako). For counterstaining the hematoxylin was used (Khan et al., 2001; Santelices Iglesias et al., 2018). One immunostained section per uterine tissue was evaluated at a $40 \times$; a minimum of three arbitrarily chosen views with approximately 100 cells was evaluated (Kowalewski et al., 2006). Data were analyzed with GLIMMIX procedure of SAS 9.4 with Poisson distribution and log link functions (SAS Institute Inc., Cary, NC). Three orthogonal contrasts were designed to compare differences between means. Data are shown as least squares means \pm standard errors. Statistical significance was set at $p<0.05$.

\section{Ethical approval}

The experiment was carried out in accordance with international recommendations specified in the guidelines for the care and use of laboratory animals and with the recommendations of the National Academy Science concerning the use of dogs as laboratory animals, and the approval of the IACUC of the Facultad de Ciencias Veterinarias, Universidad Nacional de La Plata (40-4-14 B).

\section{Results and Discussion}

The uterine biopsies samples were classified in normal endometrium (NE; $n=15)$, acute endometritis (AE; $n=9$ ), subacute endometritis (SE; $n=7$ ), chronic endometritis (CE; $n=14$; Fig. 1$)$, cystic endometrial hyperplasia $(n=$ 1 ), and atrophy $[n=2$ (Table 1$)]$. Normal endometrium was characterized by the presence of less than three neutrophils or the absence of inflammatory cells in endometrium per $40 \times$ field (Galabova et al., 2003).
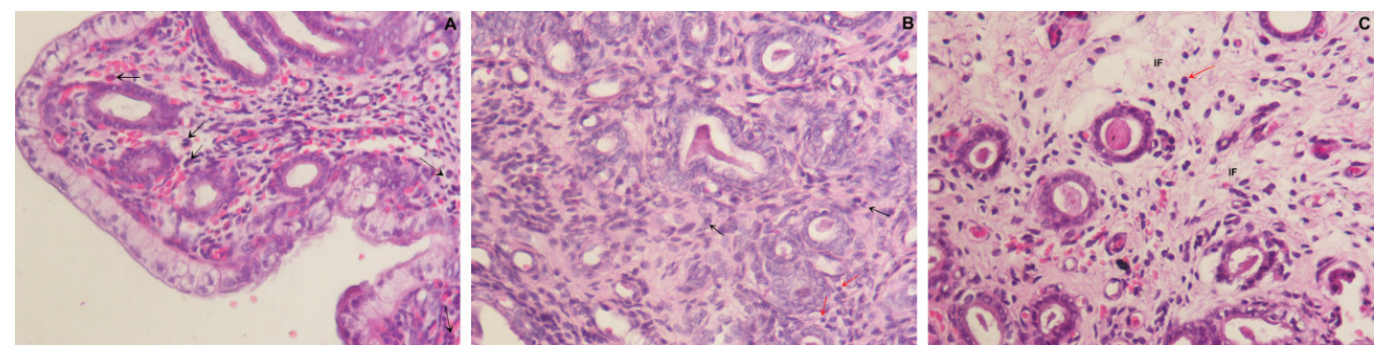

Fig. 1. Photomicrograph of endometrial tissue in a biopsy from acute endometritis (AE; A), subacute endometritis (SE; B), and chronic endometritis (CE, C). Black arrows indicate polymorphonuclear neutrophilic, red arrow indicate lymphocytes. IF: interstitial fibrosis $(40 \times, \mathrm{H} \& \mathrm{E})$. 

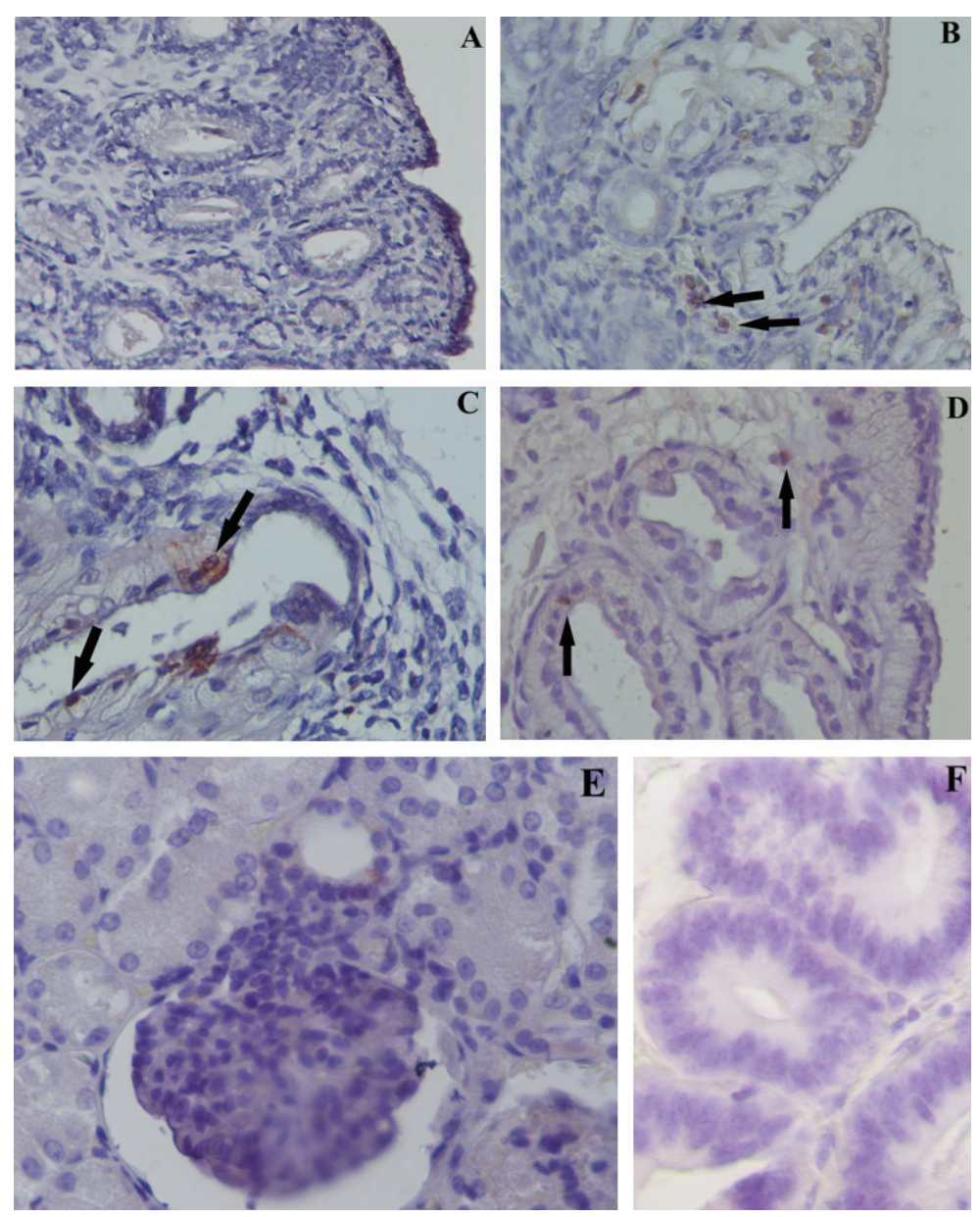

Fig. 2. Expression of COX2 by immunohistochemistry in NE (A, 40×), $\mathrm{AE}(\mathrm{B}, 60 \times)$, SE $(\mathrm{C}, 60 \times)$, and $\mathrm{CE}(\mathrm{D}, 60 \times)$. Black arrow indicates stained inflammatory cells. Positive control: Expression of COX2 in the macula densa of a section of canine kidney (E, 60×). Negative control: $(F, 60 \times)$.

Acute endometritis was characterized by the presence of neutrophils in endometrium per $40 \times$ field and the presence of hyperemia, vascular congestion, or stromal edema. Subacute endometritis was characterized by the presence of edema, polymorphonuclear, and mononuclear cells. Chronic endometritis was characterized by the presence of lymphocytes, plasma cells, and macrophage in endometrium and interstitial fibrosis (Schlafer, 2012; Gifford et al., 2014; García Mitacek et al., 2017; Praderio et al., 2019). Endometrial hyperplasia was defined by an increase in the size and number of glands with no change in the stroma except for edema, presence of hypertrophic and hyperplastic glandular cells with clear vacuolated cytoplasm. When the glands become cystic, and the epithelium of the glands becomes flattened, the biopsy was defined as cystic endometrial hyperplasia (Foster, 2012). Atrophy was defined by lining mucosa covering a thin layer of condensed stroma in the depths of which are the inactive glandular remnants (Schlafer and Foster, 2016; Praderio et al., 2019). Mean serum $\mathrm{P}_{4}$ concentrations in bitches with and without endometritis were similar (11.26 \pm 2.43 vs. $19.83 \pm 5.34$, respectively; $p>0.09$ ). Vaginal cytology samples showed between $70 \%$ and $80 \%$ intermediate cells, $10 \%-15 \%$ parabasal cells, 5\%-10\% superficial cells per field and neutrophils presence at $40 \times$ magnification. COX2 immunostaining was scattered and restricted to cells in the stroma in bitches with NE. However, in bitches with endometritis, strong staining was observed in luminal epithelium, glandular epithelium, and stromal cells (Fig. 2). Staining was also observed in inflammatory cells localized in the stroma as well as inside of the glands. The percentage of $\mathrm{COX} 2$ positive stromal cells in bitches with $\mathrm{AE}, \mathrm{SE}$, and $\mathrm{CE}$ were significantly higher compared with NE ( $p$ $<0.005)$. In addition, the percentage of COX2 positive stromal cells in bitches with SE and CE was significantly lower compared with $\mathrm{AE}(p<0.003)$. However, no differences were found in the percentage of COX2 positive stromal cells in bitches with SE compared with CE ( $p>0.33$; Fig. 3). 
Table 1. Data of the age, breed, parity and days post-estrus at the time of OVX in bitches include in the study.

\begin{tabular}{|c|c|c|c|c|c|}
\hline Bitch & Age (years) & Breed & Number of Parity & $\begin{array}{l}\text { Days post-estrus at the time } \\
\text { of ovariohysterectomy }\end{array}$ & Uterine biopsies samples \\
\hline 1 & 2 & Mixed & 0 & 50 & $\mathrm{NE}$ \\
\hline 2 & 2 & Mixed & 1 & 45 & $\mathrm{NE}$ \\
\hline 3 & 2 & Mixed & 0 & 50 & NE \\
\hline 4 & 1 & Mixed & 0 & 15 & NE \\
\hline 5 & 1 & Mixed & 0 & 50 & NE \\
\hline 6 & 4 & Mixed & 0 & 35 & $\mathrm{NE}$ \\
\hline 7 & 2 & Mixed & 0 & 50 & $\mathrm{NE}$ \\
\hline 8 & 1 & Mixed & 0 & 30 & $\mathrm{NE}$ \\
\hline 9 & 4 & Mixed & 1 & 43 & $\mathrm{NE}$ \\
\hline 10 & 5 & Mixed & 0 & 50 & $\mathrm{NE}$ \\
\hline 11 & 1 & Mixed & 0 & 15 & NE \\
\hline 12 & 2 & Mixed & 0 & 30 & NE \\
\hline 13 & 1 & Mixed & 0 & 15 & NE \\
\hline 14 & 2 & Mixed & 0 & 15 & $\mathrm{NE}$ \\
\hline 15 & 2 & Mixed & 0 & 50 & $\mathrm{NE}$ \\
\hline 16 & 3 & Mixed & 0 & 15 & $\mathrm{AE}$ \\
\hline 17 & 5 & Mixed & 0 & 30 & $\mathrm{AE}$ \\
\hline 18 & 5 & Mixed & 0 & 50 & $\mathrm{AE}$ \\
\hline 19 & 3 & Mixed & 0 & 43 & $\mathrm{AE}$ \\
\hline 20 & 1 & Mixed & 0 & 45 & $\mathrm{AE}$ \\
\hline 21 & 1 & Mixed & 0 & 48 & $\mathrm{AE}$ \\
\hline 22 & 1 & Mixed & 0 & 33 & $\mathrm{AE}$ \\
\hline 23 & 5 & Mixed & 0 & 15 & $\mathrm{AE}$ \\
\hline 24 & 1 & Mixed & 0 & 50 & $\mathrm{AE}$ \\
\hline 25 & 1 & Mixed & 0 & 50 & SE \\
\hline 26 & 1 & Mixed & 0 & 45 & SE \\
\hline 27 & 3 & Mixed & 0 & 15 & SE \\
\hline 28 & 1 & Mixed & 0 & 20 & SE \\
\hline 29 & 1 & Mixed & 0 & 43 & SE \\
\hline 30 & 3 & Mixed & 2 & 19 & SE \\
\hline 31 & 1 & Mixed & 0 & 50 & SE \\
\hline 32 & 2 & Mixed & 0 & 50 & $\mathrm{CE}$ \\
\hline 33 & 4 & Mixed & 0 & 50 & $\mathrm{CE}$ \\
\hline 34 & 1 & Mixed & 0 & 50 & $\mathrm{CE}$ \\
\hline 35 & 1 & Mixed & 0 & 30 & $\mathrm{CE}$ \\
\hline 36 & 2 & Mixed & 1 & 17 & $\mathrm{CE}$ \\
\hline 37 & 2 & Mixed & 2 & 32 & $\mathrm{CE}$ \\
\hline 38 & 1 & Mixed & 0 & 32 & $\mathrm{CE}$ \\
\hline 39 & 2 & Mixed & 0 & 50 & $\mathrm{CE}$ \\
\hline 40 & 2 & Mixed & 0 & 22 & $\mathrm{CE}$ \\
\hline 41 & 2 & Mixed & 0 & 43 & $\mathrm{CE}$ \\
\hline 42 & 3 & Mixed & 1 & 20 & $\mathrm{CE}$ \\
\hline
\end{tabular}




\begin{tabular}{cccccc}
\hline Bitch & Age (years) & Breed & Number of Parity & $\begin{array}{c}\text { Days post-estrus at the time } \\
\text { of ovariohysterectomy }\end{array}$ & Uterine biopsies samples \\
\hline 43 & 5 & Mixed & 0 & 50 & CE \\
44 & 1 & Mixed & 0 & 15 & CE \\
45 & 2 & Mixed & 0 & 30 & CE \\
46 & 3 & Mixed & 0 & 50 & Cystic endometrial hyperplasia \\
47 & 1 & Mixed & 0 & 50 & Atrophy \\
48 & 1 & Mixed & 0 & 33 & Atrophy \\
\hline
\end{tabular}

NE: normal endometrium; AE: acute endometritis; SE: subacute endometritis; CE: chronic endometritis.

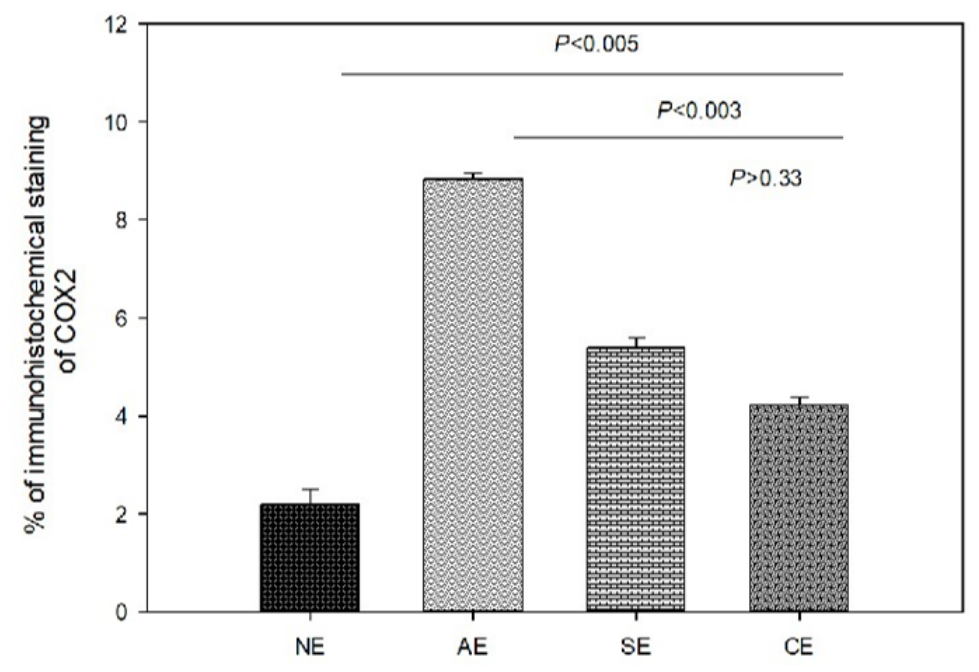

Fig. 3. Percentage of immunohistochemical staining of COX2 in stromal cells in bitches with NE, AE, SE, and CE.

Immunohistochemical expression of COX2 in the endometrial epithelium and stromal cells was also observed in cases of pyometra in the bitch. In addition, the COX2 expression was higher at the glandular and luminal epithelium as well as in the inflammatory cells in bitches with pyometra compared with control group (Silva et al., 2010). Similarly, in our work, we observed the expression of COX2 in the luminal epithelium, glandular epithelium, and stromal cells in bitches with endometritis without the presence of cystic endometrial hyperplasia. In woman, Chishima et al. (2002) observed that COX2 staining was denser in the ectopic endometriosis implants when compared with eutopic endometrium (Chishima et al., 2002). In addition, Ota et al. (2001) found that the expression of COX2 in the glandular epithelium was higher from endometriosis samples compared with control group. In contrast with our results, in woman no differences in the expression of COX2 in stromal cells were found in endometriosis compared with control group; however, the expression tended to be slightly higher (Ota et al., 2001).

It has been reported that $\mathrm{COX} 2$ in normal uterine tissue is concerned in cell proliferation and regeneration, promotion of angiogenesis, and immunity (Chishima et al., 2002). On the other hand, several reproductive disorders showed a high expression of COX2. This fact has been correlated with pathological abnormalities, such as infertility (Ota et al., 2001; Chishima et al., 2002). Therefore, is considered that high expression of COX2 with abnormal prostaglandin generation contributes to the pathophysiology of uterine diseases (Chishima et al., 2002).

In conclusion, our results showed that the percentage of COX2 positive stromal cells in bitches with endometritis was significantly higher compared with NE. This fact could be involved in the pathophysiological mechanisms in $\mathrm{CHB}$ showing endometritis without cystic endometrial hyperplasia. However, further research studies into the involvement of COX2 in bitches are required. 


\section{Acknowledgments}

The authors would like to thank Dr. Adriana Massone and Dr. Gonzalo Madariaga (Laboratory of Veterinary Pathology Dr. B. Epstein, FCV UNLP) for her help in performed and classified the uterine samples.

\section{Conflict of interest}

The authors declare that there is no conflict of interest. Funding

This study was supported in part by UNLP grant V11/230 to RL de la Sota and MA Stornelli and by a PICT grant 2014-1900 to MC García Mitacek. Also, MC García Mitacek was supported by an assistant researcher fellowship from CONICET.

\section{Authors contribution}

García Mitacek MC helped to design, conduct the experiment, and process the samples, analyzed data and drafted the manuscript. Stornelli MC and Praderio $\mathrm{R}$ helped to conduct the experiment and process the samples. De la Sota RL and Stornelli MA helped to design and conduct the experiment and critically revised the manuscript.

\section{References}

Bukowska, D., Kempisty, B., Zawierucha, P., Jopek, K., Piotrowska, H., Antosik, P., Ciesiółka, S., Woźna, M., Brüssow, K.P. and Jaśkowski, J.M. 2014. Microarray analysis of inflammatory responserelated gene expression in the uteri of dogs with pyometra. J Biol. Regul. Homeost. Agents 28(4), 637-48.

Chishima, F., Hayakawa, S., Sugita, K., Kinukawa, N., Aleemuzzaman, S., Nemoto, N., Yamamoto, T. and Honda, M. 2002. Increased expression of cyclooxygenase-2 in local lesions of endometriosis patients. Am. J. Reprod. Immunol. 48(1), 50-6.

De Bosschere, H., Ducatelle, R., Vermeirsch, H., Van Den Broeck, W. and Coryn, M. 2001. Cystic endometrial hyperplasia-pyometra complex in the bitch: should the two entities be disconnected? Theriogenology 55(7), 1509-19.

Dow, C. 1959. The cystic hyperplasia-pyometra complex in the bitch. J. Comp. Pathol. 69, 237-50.

Feldman, C.E. and Nelson, R.W. 2000. Endocrinología y reproducción en perros y gatos, 2nd ed. México, México: Mc Graw-Hill Interamericana.

Fontaine, E., Levy, X., Grellet, A., Luc, A., Bernex, F., Boulouis, H.J. and Fontbonne, A. 2009. Diagnosis of endometritis in the bitch: a new approach. Reprod. Domest. Anim. 44, 196-9.

Foster, R.A. 2012. Chapter 18. Female reproductive system and mammary gland. In: Pathologic basis of veterinary disease, 5th ed. Eds., Zachary, J.F. and McGavin, M.D. Amsterdam, Netherlands: Elsevier, pp: $1085-127$.

Galabova, G., Egerbacher, M., Aurich, J.E., Leitner, M. and Walter, I. 2003. Morphological changes of the endometrial epithelium in the bitch during metoestrus and anoestrus. Reprod. Domest. Anim. 38, 415-20.

García Mitacek, M.C., Praderio, R.G., Stornelli, M.C., de la Sota, R.L. and Stornelli, M.A. 2017. Prostaglandin synthesis enzymes' gene transcription in bitches with endometritis. Reprod. Domest. Anim. 52, 298-302.

Gifford, A.T., Scarlett, J.M. and Schlafer, D.H. 2014. Histopathologic findings in uterine biopsy samples from subfertile bitches: 399 cases (1990-2005). J. Am. Vet. Med. Assoc. 244, 180-6.

Haas, M., Kaup, F.J. and Neumann, S. 2016. Canine pyometra: a model for the analysis of serum CXCL8 in inflammation. J. Vet. Med. Sci. 78(3), 375-81.

Hagman, R. 2017. Molecular aspects of uterine diseases in dogs. Reprod. Domest. Anim. 52(3), 37-42.

Khan, K.N., Stanfield, K.M., Trajkovic, D. and Knapp, D.W. 2001. Expression of cyclooxygenase-2 in canine renal cell carcinoma. Vet. Pathol. 38(1), 116-9.

Kowalewski, M.P., Schuler, G., Taubert, A., Engel, E. and Hoffmann, B. 2006. Expression of cyclooxygenase 1 and 2 in the canine corpus luteum during diestrus. Theriogenology 66(6-7), 1423-30.

Mir, F., Fontaine, E., Albaric, O., Greer, M., Vannier, F., Schlafer, D.H. and Fontbone, A. 2013. Findings in uterine biopsies obtained by laparotomy from bitches with unexplained infertility or pregnancy loss: an observational study. Theriogenology 79(2), 312-22.

Ota, H., Igarashi, S., Sasaki, M. and Tanaka, T. 2001. Distribution of cyclooxygenase-2 in eutopic and ectopic endometrium in endometriosis and adenomyosis. Hum. Reprod. 16(3), 561-66.

Praderio, R.G., García Mitacek, M.C., Núñez Favre, R., Rearte, R., de la Sota, R.L. and Stornelli, M.A. 2019. Uterine endometrial cytology, biopsy, bacteriology, and serum C-reactive protein in clinically healthy diestrus bitches. Theriogenology 131, 153-61.

Santelices Iglesias, O.A., Wright, C, Duchene, A.G., Risso, M.A., Risso, P, Zanuzzi, C.N., Nishida, F., Lavid, A., Confente, F., Díaz, M., Portiansky, E.L., Gimeno, E.J. and Barbeito, C.G. 2018. Association between degree of anaplasia and degree of inflammation with the expression of COX-2 in feline injection site sarcomas. J. Comp. Pathol. 165, 45-51.

Schlafer, D.H. 2012. Diseases of the canine uterus. Reprod. Domest. Anim. 47, 318-22.

Schlafer, D.H. and Foster, R.A. 2016. Female genital system. Pathology of the genital of the nongravid female. In Jubb Kennedy \& Palmer's. Pathology of domestic animals (3), 6th ed. Ed., Maxie, M.G. Saint Louis, MO: Elsevier, pp: 358-464.

Schlafer, D.H. and Miller, R. 2007. Pathology of the female reproductive system. In Jubb Kennedy and Palmer's pathology of domestic animals, 5th 
ed. Ed., Maxie, M.G. Philadelphia, PA: Elsiever Saunders, vol 3, pp: 429-564.

Silva, E., Leitao, S., Henriques, S., Kowalewski, M.P., Hoffmann, B., Ferreira-Dias, G., da Costa, L.L. and Mateus, L. 2010. Gene transcription of TLR2,
TLR4, LPS ligands and prostaglandin synthesis enzymes are up-regulated in canine uteri with cystic endometrial hyperplasia-pyometra complex. J. Reprod. Immunol. 84, 66-74. 